\title{
Assessment of the Status of SPM in Jammu City and its Control Strategies
}

\author{
Angelika Sharma* and A.K Raina** \\ *Assistant professor, Department of Environment Sciences, Central university, Jammu, \\ **Professor, Department of Environment Sciences, university of Jammu, Jammu
}

\begin{abstract}
Suspended particulate matter is considered to be a major air pollutant which is deteriorating plant and animal life. The Particulate matter, particularly less than 10 micron in size can pass through the natural protective mechanism of human respiratory system and play very important role in genesis augmentation of health problems. Ambient air quality was monitored along with the seasonal variations and results are discussed. For the mitigation of air pollution problem in the city, the different control strategies have been discussed.
\end{abstract}

Keywords:Suspended Particulate Matter, Vehicular Emissions and High Volume Air Sampler

\section{Introduction}

The amount of pollutants released in the atmosphere by fixed/stationary or mobile anthropogenic source is associated with economic activities, and occur when the scale of waste disposal exceeds the assimilative capacity of environment.

The progressive increase in urbanization in recent years, although has positive role in developmental process, but at the same time it imposes unending challenges such as inadequate water supply, improper sanitation and waste disposal, traffic congestion and environmental pollution. Deterioration of air quality is a major environmental problem in many urban centres in both developed and developing countries. Root cause of urban air pollution is the continuous rise in number and types of vehicle population.

Rise in number and types of vehicles along with lack of smooth traffic flow due to congested and narrow roads results in frequent traffic jams. This further aggravates the problem of air pollution. Among all the types of vehicles, predominant mobile air pollution source in all the industrialized countries of the world is the automobile powered by a four-stroke cycle engine and using gasoline as a fuel. Other causes are exponential growth of population, rapid proliferation of industries and technological development/advances.

Emission of pollutants from the vehicles also depends upon the type of fuel used. Diesel engines have substantial emissions of which particulate matter and $\mathrm{SO}_{2}$ is vital. Petrol run vehicles emit $\mathrm{CO}$, hydrocarbons, lead and oxides of nitrogen in the atmosphere. The particulate matter, important from air pollution point of view, may range from 0.01 to 100 in diameter. In urban areas, particulates emanate from a variety of sources such as cars, trucks, buses, factories, construction sites, tilled fields, unpaved roads, stone crushers and burning of wood and fossil fuels (Street et al, 1996).

The respirable particulate matter (RSPM or $\left.\mathrm{PM}_{10} \leq 10 \mathrm{~m}\right)$ are trapped in conducting airway and fine particulate matter $\left(\mathrm{PM}_{2.5}\right.$ or $\left.2.5 \mathrm{~m}\right)$ are trapped in respiratory airways of human lungs. Some of the particles mainly above $2.5 \mathrm{~m}$ can be removed from the air by rain fall, particles also disappear from the air by impinging on objects such as trees, animals and buildings. Extremely small particles do not readily impinge on objects due to their aerodynamic properties.

The respirable particulate matter and fine particulate matter are of more concern from public health point of view (Rajesekhar et al, 2001). These particles of smaller size, particularly of $1 \mathrm{~m}$ cause health hazards as these are most liable to enter the respiratory tract and get lodged in the air spaces of lungs.

Thus, it is necessary to evaluate the status of suspended particulate matters in the existing air quality of any area for the better management practices. An attempt have been made in the present study to evaluate the status of suspended particulate matter (SPM) in the city of Jammu and some strategies for controlling air pollution have also been discussed.

\section{Description Of The Study Area}

Jammu, latitude $32^{\circ} 44^{\prime} \mathrm{N}$, longitude $74^{0} 55^{\prime} \mathrm{E}$ and at about $400 \mathrm{~m}$ altitude (msl), the winter capital of Jammu and Kashmir state, covers an area of approximately 3,250 sq km. It is separated from Bahu-Mahamaya feature by Tawi river which is a tributary of river Chenab.

Jammu city is located on the Shivalik hill-lock of the Himalayas on the National Highway No. IA, the only road which connects Srinagar, the summer capital of Jammu and Kashmir, to the rest of the country. 
Jammu district, situated in the sub-tropical part has a markedly periodic climate. It is characterized by a dry and increasing hot season from March to June, a warm monsoon period from July to October and cold weather from November to February with little winter rain during the month of January.

The rainy season (July-October) starts with the break of southwest monsoon. The annual rainfall of Jammu is $1,113.6 \mathrm{~mm}$. Of this nearly $72 \%$ is received during monsoon period. Jammu experiences great extremes of temperatures with hot summers and cold winters.

Jammu, once regarded as the city of temples, is now better recognized as the city of traffic congestion and bad air. A no care attitude and gross negligence coupled with ever increasing needs and demands over the years have taken the problem of air pollution to threatening dimensions. In the absence of any major industry in and around Jammu city, vehicular emissions is the major pollution source and is assuming alarming proportion in Jammu.

Mobile sources, therefore, consist of many different types of vehicles, powered by engines using different cycles, fueled by variety of products and emitting varying amounts of both simple and complex pollutants.

The predominant mobile air pollution source in all the industrialized countries of the world is the automobiles, powered by four cycle engine and using gasoline as the fuel.

The number of vehicles has almost doubled during the $10^{\text {th }}$ plan. At present approximately 47,000 vehicles are registered at Jammu Road Transport Office (RTO) annually. Most of the vehicles plying in the city are required to move at slow speed with low gear and frequent use of clutch due to hilly terrain (Sharma, 2000). Moreover, the uncontrolled and awfully mixed vehicular density or insufficient and badly cared road space, lack of adequate parking facilities, undisciplined drivers, indifferent pedestrians together with a bad traffic management strategy, which is far from the ideal have profound effect on urban air pollution.

Emissions of pollutions from vehicles also depend upon the type of fuel used. According to Ray (2001), urban transport sector is a major consumer of energy and accounts for about $75 \%$ of the diesel consumed in India. Diesel engines have substantial emissions of which particulate matter and $\mathrm{SO}_{2}$ is vital. Most particulate matter results from incomplete combustion of the fuel. During power-cuts, a large number of generators also contribute pollutant. Coal is also a major fuel used by roadside shops and tea stalls. LPG is used as a fuel by about $50 \%$ of population. Industrial areas have been set-up outside the city. Thus, in the absence of any major industry in the Jammu city, vehicles remain to be the major polluters of existing air quality.

\section{Methodology Adopted}

To quantify SPM emissions and to study the ambient air pollution due to vehicular emissions, three residential areas (Panjtirthi, Karan Nagar, Green Belt); three commercial areas (Kachi Chawni, Raghunath Bazar, Gole Market); and three traffic crossings (Vikram Chowk, Rehari Chowk and Satwari Chowk) have been identified after a thorough survey of the city.

Air sampling was carried out for 2 years on monthly basis from January, 2004 to December, 2005 during day time at each site for a period of 8 hours and analysed for SPM in accordance with the standards prescribed by the Bureau of Indian Standards (BIS) - BIS 5182.

For the collection of samples of suspended particulate matter (SPM), glass fiber filter paper (GF/A) was used in an Envirotech APM 415 Air Sampler. The flow rate was maintained at $1.5 \mathrm{~m}^{3} / \mathrm{min}$ that allows the SPM to deposit on the filter paper.

\section{Results And Discussion} Table 1.

The summarized data of average concentration of SPM for the study period have been presented in

In the residential areas, the average concentration of SPM during $1^{\text {st }}$ year varies between $276.19 \mu \mathrm{g} / \mathrm{m}^{3}$ to $363.14 \mu \mathrm{g} / \mathrm{m}^{3}$ and during $2^{\text {nd }}$ year there values varies between $333.74 \mu \mathrm{g} / \mathrm{m}^{3}$ to $403.80 \mu \mathrm{g} / \mathrm{m}^{3}$. In the commercial areas, the average concentration of SPM during $1^{\text {st }}$ year varies between $485.48 \mu \mathrm{g} / \mathrm{m}^{3}$ to 782.32 $\mu \mathrm{g} / \mathrm{m}^{3}$, whereas during $2^{\text {nd }}$ year there value varies between $518.38 \mu \mathrm{g} / \mathrm{m}^{3}$ to $788.49 \mu \mathrm{g} / \mathrm{m}^{3}$. At the traffic crossings, the average concentration of SPM during $1^{\text {st }}$ year varies between $711.75 \mu \mathrm{g} / \mathrm{m}^{3}$ to $991.19 \mu \mathrm{g} / \mathrm{m}^{3}$ and during $2^{\text {nd }}$ year there values varies between $737.63 \mu \mathrm{g} / \mathrm{m}^{3}$ to $1014.30 \mu \mathrm{g} / \mathrm{m}^{3}$ (Fig. 1).

The concentration of SPM has been observed to be always higher in commercial areas and traffic crossings in comparison to the residential areas. In commercial areas, the maximum concentration of SPM has been recorded in Site IV (Kachi Chawni), whereas higher levels of SPM have been recorded at Satwari Chowk. Higher concentration of SPM in commercial areas has been attributed to mini-bus stand for passengers, autorickshaw stand and a parking place for four-wheelers in the vicinity. Use of generators during the frequent power cuts, narrow and poorly maintained roads, frequent traffic jams, slow speed of vehicles also contribute for the increase in the concentration of these gases which is further aggravated by the presence of high buildings on the sides of the road that often give less scope for the dispersion of air pollutants (Sharma et al, 2005). 
Sharma (2000) have also pointed out that the vehicles plying on the road are not specially designed for this part of the city as these are required to move at slow speed with low gear and frequent use of clutch due to hilly terrain.

The vehicular emissions are exacerbated by the age of the vehicle fleet and the poor state of vehicle maintenance (ARAI, 1998).

Higher concentrations of SPM at Jammu cantonment crossing can be attributed to the open environment giving less scope to the particulates to settle or impinge on objects and remain suspended in the environment. Moreover, the presence of a school playground there, which is not evenly covered by grass, may lead to more suspension of particulates in the air. It have been reported that the emissions from diesel vehicles contain more SPM than emission from petrol vehicles. Likewise, the increase in SPM can be clearly correlated to the composition of traffic particularly that of diesel vehicles such as trucks, buses and army vehicles which are highest on this road as it is the common route of heavy traffic to inter- and intra-state destinations.

Analysis of the data on seasonal basis revealed lower concentration of SPM in pre-monsoon and postmonsoon period including the winter for all the sites except for Raghunath Bazar and Rehari Chowk (Table 2). In the monsoon season, pollutants get washed and settle down on the earth due to heavy rainfall and thunder, therefore, the quality of ambient air is good in this season. The concentration of particulate matter was remarkably decreased in this season as compared to other seasons (Fig. 2). This is significant as it establishes the correlation between the meterological factors and pollutant concentrations. The high relative humidity, moderate temperature and heavy rains result in the decrease of concentration of particulate matter. Lower value of SPM contents during post-monsoon period may be attributed to light wind and precipitation that prevails in winter months. These factors lead to dispersion of pollutants near the source resulting into less concentration of pollutants during the winter or post-monsoon period. Low value of pollutants during the post-monsoon period is also in line with the findings of Tripathi and Panigrahi (2000) and Sehra (2007).

Based on the present study, following recommendations/suggestions for the improvement of the air quality in Jammu city have been made. Common man should be made aware of pollution and its related problems. Catalytic converters, evaporative emission control system, exhaust gas recirculating system and ignition timing based vehicles should only be allowed on the roads in future. Catalytic converter and other fitters should be made compulsory for new vehicles as well as old. The newer standards (Bharat III and IV) need to be followed.

Use of clean substitute fuels such as CNG, oxygenated blends, propane (LPG) should be encouraged. Vehicle license could be introduced which could be issued based on vehicle condition, fuel consumption and pollution emission and those failing to satisfy the condition should be penalised accordingly.

Improvement is required in road quality of Jammu city. The potholes, speed barkers, encroachments, narrow roads contribute a great deal of pollution and higher consumption of fuel. The old and poorly maintained vehicles should be phased out from the city gradually by giving definite time frame.

The entry of heavy vehicles in the city should be prohibited/directed during day hours. Proper traffic signaling system should be introduced for the regulation of traffic so that free and uninterrupted flow of traffic is maintained. This would also reduced the traffic jams because of the mismanagement particularly at the traffic crossings/rotary. A proper plan of traffic movement should be maintained for the various roads and implemented strictly for the smooth flow of traffic in old and new parts of the city. Development of parking places and inculcating of movement in group on sharing basis should be encouraged.

Certain congested commercial areas like Raghunath Bazar requires complete prohibition of entry and parking of any type of vehicles in the area during day hours.

Good quality unleaded petrol should be used. The quality of fuel should be upgraded through reduction of sulphur, tetracity lead and aromatics and an increase in octane number. The norms should be monitored by strict regulations and heavy fines on polluters. Electrical vehicles can be operated within certain limits. Green belt should be designed and developed in and around the city. The scavenging properties of plant must be exploited in making green city.

Table 1: Average concentration of SPM $\left(\mu \mathrm{g} / \mathrm{m}^{3}\right)$ at different sites of the study for the period of 2 years

\begin{tabular}{|c|c|c|c|c|c|c|}
\hline \multirow{2}{*}{ Sites } & \multicolumn{3}{|l|}{$1^{\text {st }}$ year } & \multicolumn{3}{|l|}{$2^{\text {nd }}$ year } \\
\hline & Average & Minimum & Maximum & Average & Minimum & Maximum \\
\hline \multicolumn{7}{|l|}{ Residential areas } \\
\hline Site I - Panjtirthi & 276.19 & 144.56 & 751.63 & 333.74 & 142.71 & 542.49 \\
\hline Site II - Karan Nagar & 363.14 & 108.00 & 869.23 & 403.80 & 117.77 & 789.21 \\
\hline Site III - Green Belt & 338.69 & 127.71 & 768.61 & 365.32 & 138.82 & 813.24 \\
\hline
\end{tabular}


Assessment of the Status of SPM in Jammu City and its Control Strategies

\begin{tabular}{|l|l|l|l|l|l|l|}
\hline \multicolumn{7}{|l|}{ Commercial Areas } \\
\hline Site IV - Kachi Chawni & 782.32 & 535.68 & 1136.45 & 788.49 & 519.23 & 1342.67 \\
\hline Site V - Raghunath Bazar & 560.67 & 397.33 & 977.61 & 583.20 & 374.52 & 859.35 \\
\hline Site VI - Gole Market & 485.48 & 115.23 & 684.23 & 518.38 & 262.69 & 689.81 \\
\hline Traffic Crossings & 908.62 & 169.84 & 1461.86 & 933.06 & 635.87 & 1556.36 \\
\hline Site VII - Vikram Chowk & 906 & 737.63 & 412.15 & 1681.03 \\
\hline Site VIII - Rehari Chowk & 711.75 & 402.38 & 965.33 & 733 & 2440.89 \\
\hline Site IX - Satwari Chowk & 991.19 & 668.33 & 2316.43 & 1014.30 & 604.27 & \\
\hline
\end{tabular}

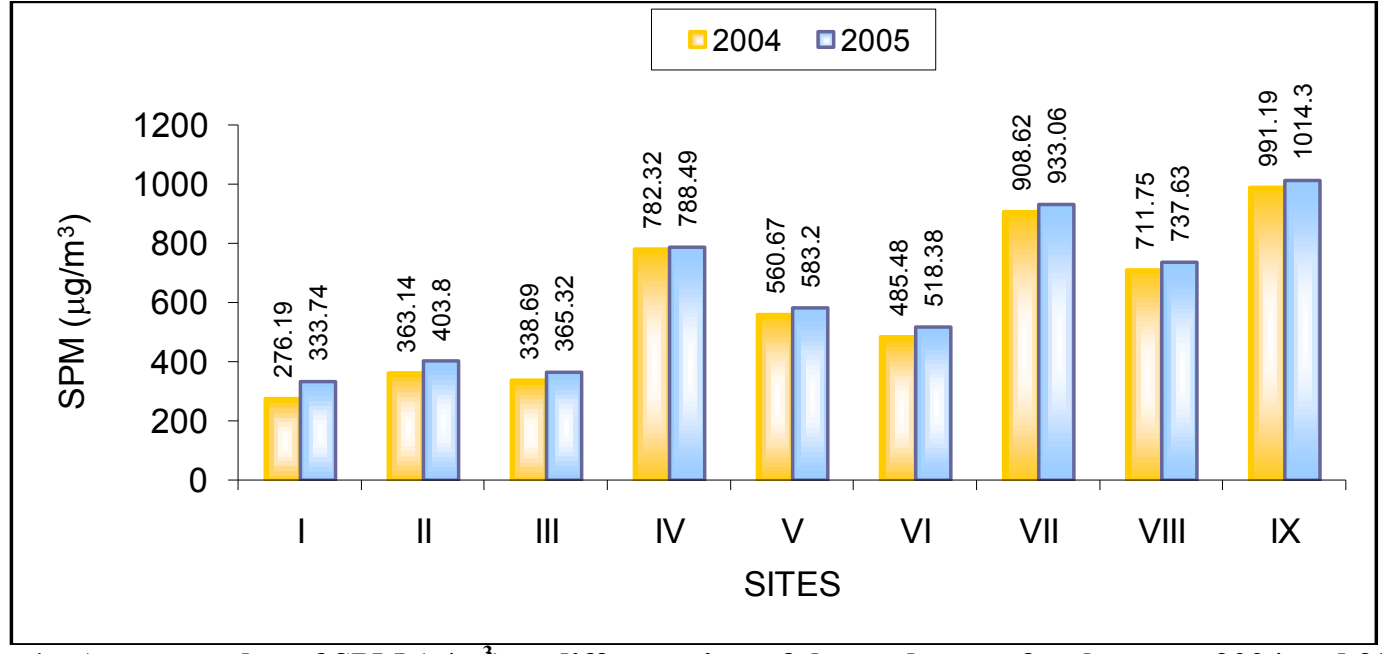

Fig. 1 : Average value of SPM $\left(\mathrm{g} / \mathrm{m}^{3}\right)$ at different sites of the study area for the years 2004 and 2005

Table 2: Seasonal variations of SPM $\left(\mu \mathrm{g} / \mathrm{m}^{3}\right)$ contents at different sites of the study area

\begin{tabular}{|l|l|l|l|}
\hline Sites & Pre-monsoon & Monsoon & Post-monsoon \\
\hline Site I - Panjtirthi & 393.41 & 228.02 & 293.46 \\
\hline Site II - Karan Nagar & 447.19 & 427.54 & 275.68 \\
\hline Site III - Green Belt & 389.96 & 359.65 & 306.40 \\
\hline Site IV - Kachi Chawni & 966.76 & 650.43 & 739.03 \\
\hline Site V - Raghunath Bazar & 556.85 & 585.87 & 573.09 \\
\hline Site VI - Gole Market & 587.26 & 459.45 & 459.09 \\
\hline Site VII - Vikram Chowk & 904.55 & 876.16 & 981.80 \\
\hline Site VIII - Rehari Chowk & 647.10 & 848.97 & 678.00 \\
\hline Site IX - Satwari Chowk & 1156.83 & 1039.15 & 812.26 \\
\hline
\end{tabular}




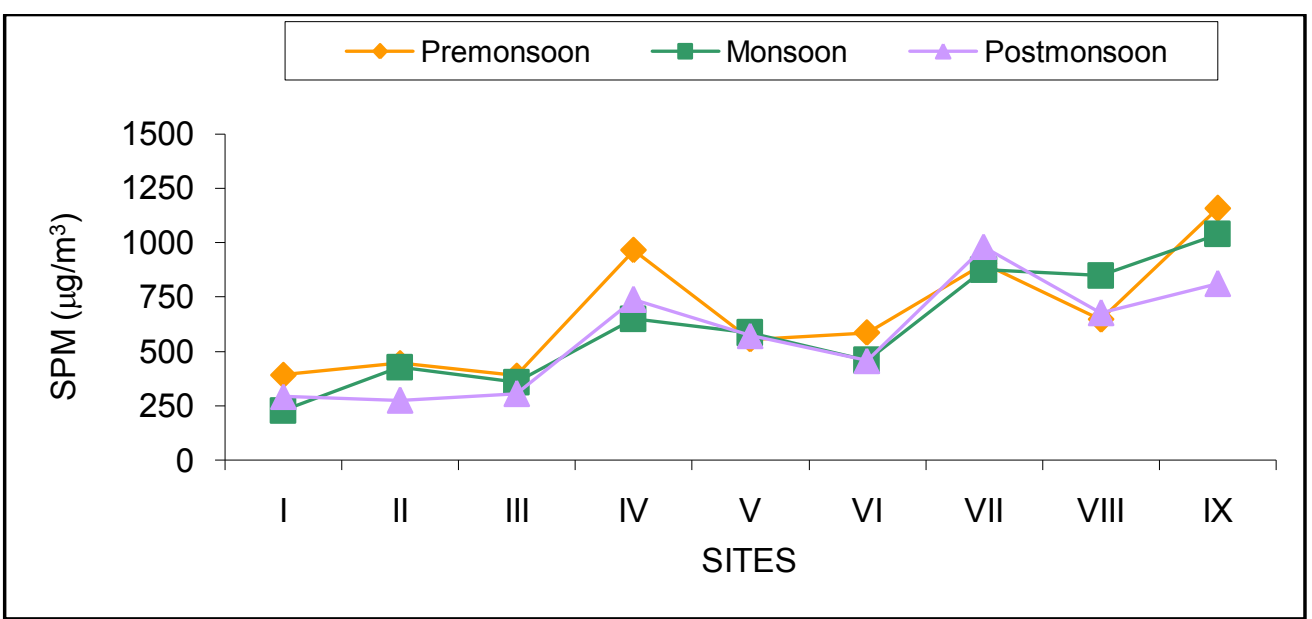

Fig. 2 : Seasonal variations of SPM $\left(\mathrm{g} / \mathrm{m}^{3}\right)$ contents at different sites of study area

\section{Conclusion}

Jammu is one of the most polluted cities in India .And in absence of any major industry in the vicinity,automobiles are the major culprits of air pollution which has attained threatening dimensions.A strategic air quality management plan has been proposed and the mitigation measures suggested to control urban air pollution would improve situation if implemented properly.

\section{References}

[1]. Rajasekhar R.V.J.,I.K Samy, M.Sridhar and P.Muthusubramaniam (2001).

[2]. Estimation of suspended particulate matter in the ambient air of Madurai City by sedimentation and filteration methods. Indian J.Env. Prot., 21 (8):673-676

[3]. Sharma, G. (2000). Growing vehicular pollution dragging Jammuities to "death trap" . Daily Excelsior XXXVI (295), October 22 (Sunday D.E. Magazine).

[4]. Ray, A. (2001). Control of vehicular pollution throygh regulation and technology.Indian Journal of transport, pp. 131-146.

[5]. Sharma,S.C.,R.Srivasatava and R.K.Roy(2005).Role of Bougainvillea in mitigation of pollution.J.Environ.Sci.Engg.,47(2):131-134

[6]. ARAI (Automotive Research Association of India) (1998).Monitoring of in-use vehical emissions.Paper presented at the workshop on Integrated Approach to Vehicular Pollution Control'.'April 16-18. New Delhi, India.

[7]. Sehra , P.S.(2007).Atmospheric pollution:A Case study of degrading urban air quality over Punjab.Indian J.Env.Prot.,27(1):32-38.

[8]. Street,R.A.,S.C.Dockham and C.N.Hewitt(1996).Laboratory and field studies of volatile organic compound emissions from sitka spruce(Picea sitchensis Bong.) in the UK.J.Geophysical Research Atmospheres, 101:22799-22806.

[9]. Tripathy,A.K.and G.P.Panigrahi(2000).Assessment of air pollution due to SPM,SO2,NOX at IRE Ltd.,Oscom Environment . Indian J. Env.Prot.,20(12):901-905. 